\title{
Two different vulvar pigmented lesions in the same patient: Basal cell carcinoma and mucosal melanosis mimicking melanoma and in-transit metastases
}

\author{
Aynı hastada iki farklı vulvar pigmentli lezyon: Bazal hücreli karsinom ve \\ melanom ve transit metastazları taklit eden mukozal melanoz
}

๑ Bengü Nisa Akay, $\odot$ Hatice Gamze Demirdağ*, ๑ylin Okcu Heper**

Ankara University Faculty of Medicine, Department of Dermatology, Ankara, Turkey

*Private Clinic, Ankara, Turkey

**Ankara University Faculty of Medicine, Department of Pathology, Ankara, Turkey

Keywords: Vulvar basal cell carcinoma, mucosal melanosis, vulvar melanoma, vulvar pigmentation, vulva, dermatoscopy, dermoscopy

Anahtar Kelimeler: Vulvar bazal hücreli karsinom, mukozal melanoz, vulvar melanom, vulva pigmentasyonu, vulva, dermatoskopi, dermoskopi

\section{Introduction}

Basal cell carcinoma (BCC) is the most common malignant skin cancer of the head and neck region. Vulvar BCC accounts for less than $1 \%$ of all BCCs and represents less than $5 \%$ of all vulvar cancers. The postmenopausal females are mostly affected and the most common site is labium majus? ${ }^{1}$. Vulvar melanosis is the most frequent lesion among genital pigmented disorders. It usually occurs in white women and has a benign course with its melanoma-like presentation². Herein, we report a case of vulvar BCC on labium majus and vulvar melanosis at the side of BCC dermatoscopically mimicking melanoma and in-transit metastasis.

\section{Case Report}

A 69-year-old woman admitted to our department for unilateal vulvar itching and burning for the previous year. Physical examination revealed a $7 \times 8 \mathrm{~mm}$ flat pigmented plaque on the right inner surface of the labium majus and pigmented group of tiny macules on the left side of the larger lesion more than $2 \mathrm{~cm}$ from the primary lesion. There wasn't a prior history of skin cancer, or radiotherapy at that site. Dermatoscopic examination of the larger lesion showed chaos of colors and structures; eccentric radial lines, gray, black, white and pink structureless areas, black clods and polymorphic vessels including dotted, serpentine and linear vessels. There was a white halo around the lesion (Figure 1). The smaller tiny macules were composed of dermatoscopic brown-gray dots except one. That one showed a structureless eccentric black area and eccentric distribution of dark-brown dots (Figure 2). Both clinical and dermatoscopic differential diagnoses included melanoma with in-transit metastases, pigmented BCC and pigmented Paget's disease. Excisional biopsy was taken from the larger one and histopathologic examination was consistent with multifocal superfical BCC (Figure 3,4 ), and the tiny pigmented macule was consistent with mucosal melanosis (Figure 5). Since the larger one was close to surgical borders, the lesion was re-excised with 4

Address for Correspondence/Yazışma Adresi: Bengü Nisa Akay MD, Ankara University Faculty of Medicine, Department of Dermatology, Ankara, Turkey Phone: +90 5323047292 E-mail: nisaakay@gmail.com Received/Geliș Tarihi: 03.09.2020 Accepted/Kabul Tarihi: 04.09.2020 ORCID: orcid.org/0000-0002-4896-1666

CCopyright 2020 by Turkish Society of Dermatology and Venereology

Turkderm - Turkish Archives of Dermatology and Venereology published by Galenos Yayınevi. 


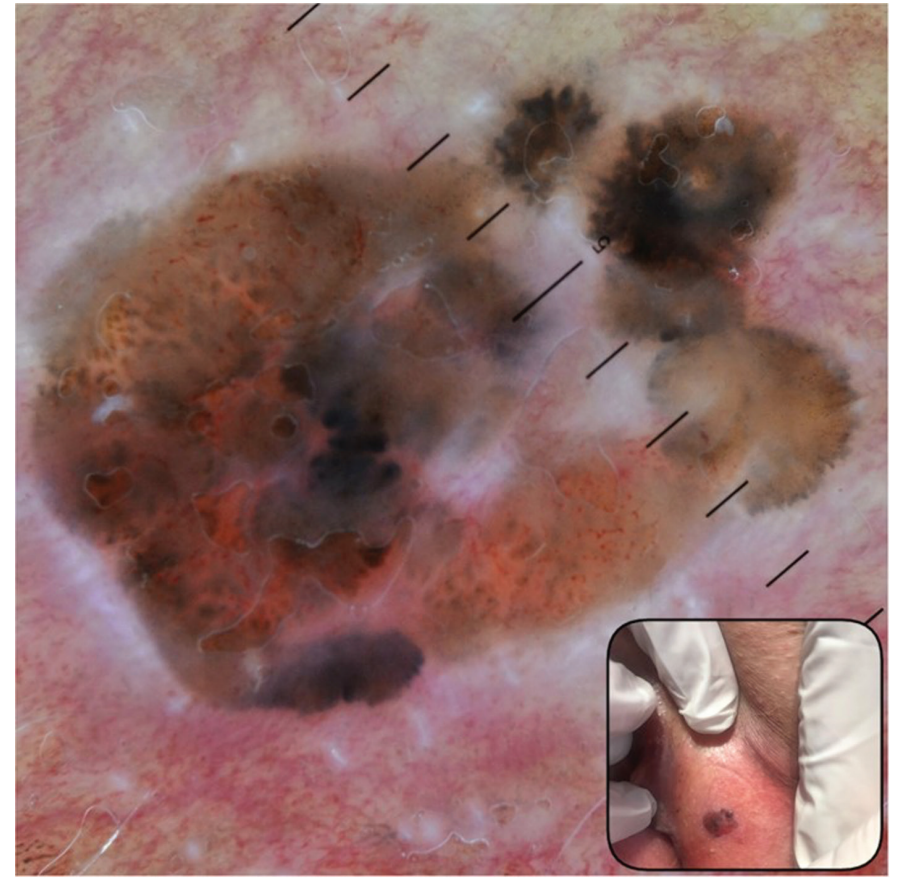

Figure 1. Dermatoscopic examination of the larger lesion showed chaos of colors and structures; eccentric radial lines, gray, black, white and pink structureless areas, black clods and polymorphic vessels including dotted, serpentine and linear vessels. There was a white halo around the lesion

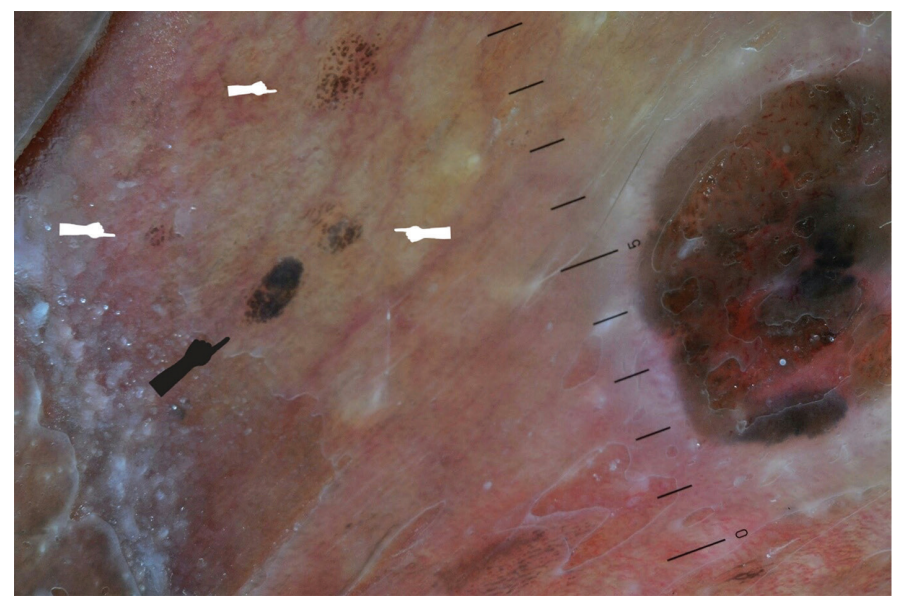

Figure 2. The smaller tiny macules were composed of dermatoscopic brown-gray dots (white hand). The darker one showed a structureless eccentric black area and eccentric distribution of dark-brown dots (black hand)

$\mathrm{mm}$ safe surgical margins. Since more aggressive variants of BCC have developed in relapsed vulvar BCC cases, it is very important to widen the surgical margins.

\section{Discussion}

The life-time ultraviolet radiation damage is the most important factor in the pathogenesis of BCC, and the vast majority is observed on sun exposed skin. Although BCCs can develop in sun protected areas, genital involvement is very rare. The etiology of BCC in sun-protected

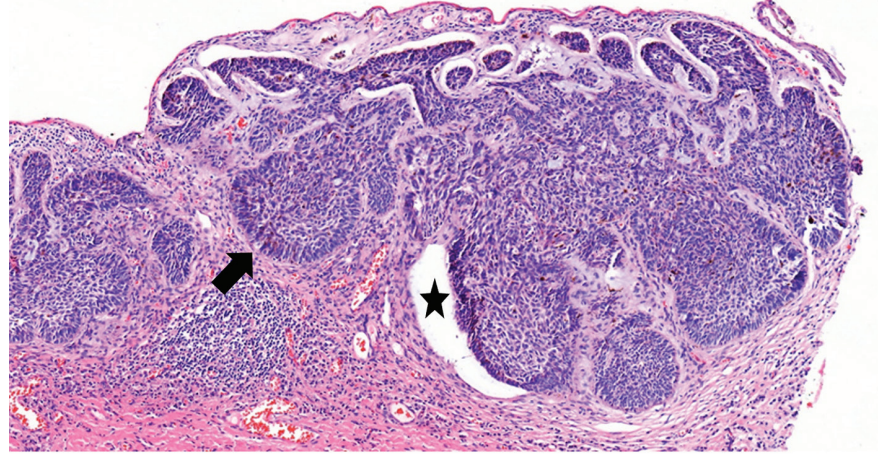

Figure 3. A tumor filled the superficial dermis causing widespread ulceration in the epidermis. It consists of epithelioid cells with narrow cytoplasm in basaloid appearance forming irregular groups. The peripheral cells of the tumor groups show palisading (arrow) and retraction artefact (asterisk); hematoxylin and eosin, x9.2 Histopathology is consistent with superficial basal cell carcinoma

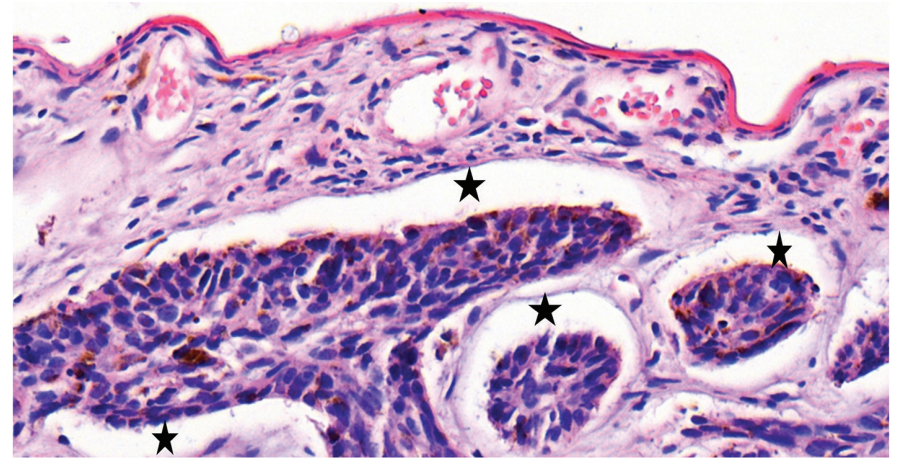

Figure 4. The melanin density on the superficial tumor areas where the retraction artefact is observed (asterisk); hematoxylin and eosin, $x 51.7$

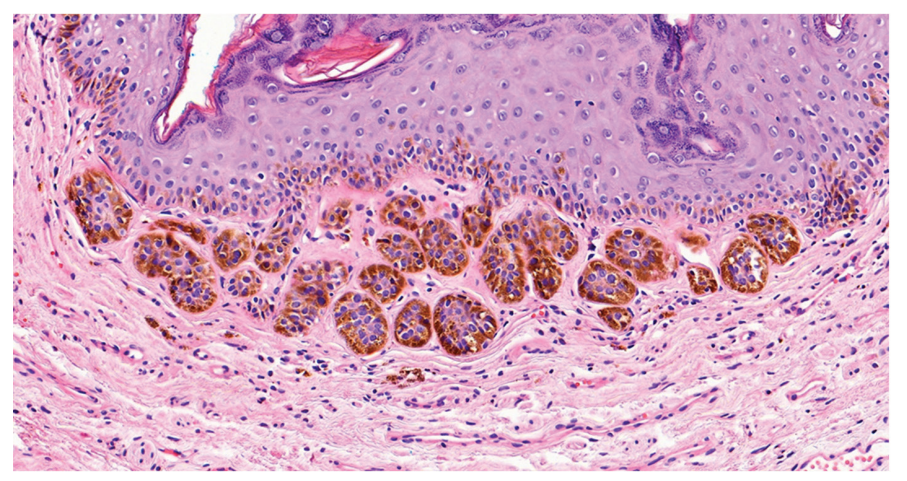

Figure 5. A very intense melanin pigment in the basal layer keratinocytes in the vulvar epidermis; hematoxylin and eosin, x23.6. Histopathology is consistent with vulvar melanotic macule (vulvar melanosis).

The microscopic figures of the case were obtained using the 3DHistech Panoramic 250 Flash digital scanner, supported by Ankara University BAP (14A0230003)

areas is unknown. Associations between genital BCC and chronic irritation, previous trauma (burn or scar), pelvic radiotherapy, preceding 
immunosuppressive therapy, arsenic, chronic inflammation secondary to underlying vulvar diseases, such as extramammary Paget disease or lichen sclerosus, genetic conditions such as Gorlin's syndrome and xeroderma pigmentosum have been reported ${ }^{1,3}$. In a systematic review describing 437 patients with vulvar BCC, it was observed that vulvar BCCs most often affect postmenopausal females over the age of 70 . The most common location was labium majus and rarely associated with underlying vulvar disease such as extramammary Paget disease or lichen sclerosus. The most common subtype of the BCC was nodular (58\%) followed by superficial (15\%), and (14\%) infiltrative subtypes ${ }^{1}$. The minority of the reported cases had BCCs on glabrous skin mainly the clitoris, labium minus, vagina/surrounding introitus, posterior fourchette and periurethral mucosa.

Pigmented skin lesions in the genital area include nevi, melanoma, melanotic macules (lentiginosis, melanosis), angiokeratomas, seborrheic keratosis, squamous cell carcinoma, and $\mathrm{BCC}^{2}$. In a study about dermatoscopy of pigmented lesions of the mucosa and the mucocutaneous junction, a structureless pattern at least in parts of the lesion and multiple colors of blue, gray, or white color are the strongest indicators to malignant mucosal lesions ${ }^{4}$. In the present case, the first impression was melanoma rather than BCC in the larger lesion, since it was presented by chaos of colors and structures; eccentric radial lines, gray, black, white and pink structureless areas, black clods and polymorphic vessels including dotted, serpentine and linear vessels which are reported dermatoscopic features of vulvar melanoma ${ }^{5}$. Besides, the smaller tiny macules were thought to be the in-transit metastasis of the main larger lesion. In transit metastases are defined as any skin or subcutaneous metastases that are more than $2 \mathrm{~cm}$ from the primary lesion but are not beyond the regional nodal basin. Lesions occurring within $2 \mathrm{~cm}$ of the primary tumor are classified as satellite metastases.

In this patient the dermatoscopic patterns of vulval melanosis were not compatible with the common described dermatoscopic patterns such as parallel, globular, and ring-like pattern ${ }^{2}$. It may be due to the small size of the lesions.

In summary, pigmented lesions on special sites can be challenging and dermatoscopy has limitations in discrimination of melanoma from nonmelanocytic neoplasms. Clinical, dermatoscopic and histopathological examinations are necessary to achieve the correct diagnosis for suspicious cases.

\section{References}

1. Renati S, Henderson C, Aluko A, Burgin S: Basal cell carcinoma of the vulva: A case report and systematic review of the literature. Int I Dermatol 2019;58:892-902.

2. Cengiz FP, Emiroglu N, Wellenhof RH: Dermoscopic and clinical features of pigmented skin lesions of the genital area. An Bras Dermatol 2015;90:17883.

3. Caucanas M, Müller G, Vanhooteghem O: Vulvar basal cell carcinoma: report of a case involving the mucosa and review of the literature. Dermatol Reports 2011;3:e37.

4. Blum A, Simionescu O, Argenziano G, et al: Dermoscopy of pigmented lesions of the mucosa and the mucocutaneous junction: results of a multicenter study by the International Dermoscopy Society (IDS). Arch Dermatol 2011;147:1181-7.

5. Oakley A: Dermatoscopic features of vulval lesions in 97 women. Australas J Dermatol 2016;57:48-53. 